\title{
Una utopía ultramontana. El papa como árbitro internacional de la paz en el siglo XIX
}

\author{
An Ultramontane Utopia. The Pope as International \\ Peace Mediator in the 19th C.
}

\author{
Francisco Javier Ramón Solans \\ Universidad de Zaragoza, España \\ fjramon@unizar.es \\ https://orcid.org/0000-0001-8667-3553
}

Recibido: 29/10/2020

Aceptado: 15/03/2021

Cómo citar este artículo: RAMÓN SOLANS, Francisco Javier (2021). Una utopía ultramontana. El papa como árbitro internacional de la paz en el siglo XIX. Pasado y Memoria. Revista de Historia Contemporánea, (23), pp. 117-138, https:// doi. org/10.14198/PASADO2021.23.05

\section{Resumen}

En la segunda mitad del siglo XIX se articuló un programa utópico en torno a la idea de un mundo bajo la influencia y la autoridad moral del pontífice. Tras la pérdida del poder temporal del papa, los católicos imaginaron nuevas formas de reinscribir su autoridad en el seno de la Iglesia católica, así como fuera de ella. Uno de los elementos centrales de esta utopía ultramontana fue el proyecto de hacer del papa el árbitro internacional de la paz. Para legitimar este programa utópico volvieron la vista atrás, hacia un pasado medieval idealizado, y trataron de encontrar referentes que demostraran su autoridad moral fuera de los marcos confesionales del catolicismo. Para estudiar estos proyectos utópicos, el presente trabajo se centra en los discursos y las solicitudes de arbitraje internacional realizados por los católicos en los congresos celebrados en España entre 1889 y 1899.

Palabras clave: Ultramontanismo; Siglo XIX; Papa; Arbitraje diplomático; Congresos católicos; España. 


\begin{abstract}
During the second half of the 19th century, a utopian project was composed around an idea of the world under the influence and the moral authority of the Pope. After the Pope's loss of power, Catholics imagined new ways to restore his authority both within ad outside the Catholic Church. Central to this ultramontane utopia was the project of turning the pope into an international peace mediator. In order to legitimise that utopian programme, they looked back to an idealised medieval past, and tried to find references to prove his moral authority outside the confessional frameworks of Catholicism. In order to study these utopian projects, this paper focuses on the speeches and requests for international arbitration made by Catholics at the congresses held in Spain between 1889 and 1899.
\end{abstract}

Keywords: Ultramontanism; 19th century; Pope; Diplomatic mediation; Catholic congresses; Spain.

Financiación: Esta investigación ha sido posible gracias al programa Ramón y Cajal (RYC2019-026405-I/AEI/10.13039/501100011033) y los proyectos de investigación «La dimensión popular de la política en la Europa Meridional y América Latina, 17891889» PID2019-105071GB-I00 y «La España global. Las identidades españolas, en perspectiva trasnacional (1780-1936)» PID2019-108299GB-C21.

El 20 de septiembre de 1870 los ejércitos italianos comandados por el general Raffaele Cadorna abrían una brecha en las murallas aurealianas cerca de la Porta Pia y conquistaban Roma. Con esta última operación militar, el reino de Italia lograba su tan ansiada capital al mismo tiempo que desaparecía uno de los Estados más antiguos de Europa: los Estados Pontificios. Desde el 751 d.C., el papa había combinado su liderazgo religioso con su con su liderazgo espiritual con su poder político como jefe de Estado de un reino que, con variaciones, había ocupado la región central de la península itálica durante más de un milenio. La noticia de los bersaglieri adentrándose en la Ciudad Santa conmocionó al mundo católico y su eco se dejó sentir en los rincones más apartados del globo. La caída de Roma se convirtió en uno de los acontecimientos más impactantes de aquel convulso año de 1870 (Pecout, 2017).

El papa se declaró prisionero en el Vaticano, excomulgó a Vittorio Emanuele II y pidió a los jefes de Estado de todo el mundo que rompiera relaciones con el monarca italiano. Si bien, con la excepción del presidente de Ecuador, Gabriel García Moreno, ningún jefe de Estado realizó una protesta formal ante el monarca italiano por la conquista de Roma, las manifestaciones de adhesión a la Santa Sede se multiplicaron por todo el mundo. Desde el laicado al episcopado, los católicos enviaron al papa numerosas muestras de apoyo que iban desde la recogida de firmas y del óbolo de San Pedro hasta el envío 
de antologías de poemas y canciones en su honor (Ramón Solans, 2020a). Pronto, cuando las circunstancias lo permitieron, los fieles acudieron a Roma a consolar para mostrar su apoyo al pontífice en multitudinarias demostraciones de masas que fueron narradas por todo el mundo (Brennan, 2000). La prensa confesional se inundó de relatos patéticos en los que se exageraba la situación del pontífice, presentándolo como un verdadero prisionero, cubierto de harapos y durmiendo en un jergón de paja, para buscar la empatía de los creyentes de todo el mundo (Seiler, 2007). Sin embargo, el dramatismo que imprimieron a estas manifestaciones de solidaridad les impidió percibir que la pérdida del poder temporal se había visto compensada por un poder todavía mayor, aquel que otorgaba al papa su nuevo rol como autoridad moral y rector de la opinión pública católica a escala global (Viaene, 2005).

En este contexto, conforme el poder terrenal del papa se iba viendo reducido, su poder global -simbólico, mediático y efectivo sobre la propia Iglesiase incrementaba exponencialmente. Uno de los factores que contribuyó al desarrollo de esta presencia global sería el papel que se le atribuyó en las relaciones internacionales. Así, desde muy pronto, los católicos comenzaron a fantasear con la idea de que el mundo diplomático estuviera regido por el papa. Este proyecto iría tomando forma en una especie de Naciones Unidas en las que el pontífice desempeñaría el papel de árbitro. Esta reivindicación se produjo tanto en plano teórico a través de numerosas obras que rescataban está perdida prerrogativa «medieval» como a nivel práctico a través de peticiones en diversos congresos y la propia actividad mediadora que desarrolló León XIII en el fin de siglo. Para los partidarios de la Santa Sede, esta actividad diplomática e intelectual suponía un «reconocimiento implícito de su soberanía» tras la pérdida de los Estados Pontificios (Ticchi, 2002: 32-33).

Para ello, nos vamos a centrar en la articulación y promoción de esta visión utópica en el marco de los congresos católicos que tuvieron lugar en España entre 1889 y 1899. Con frecuencia, la importancia de los congresos ha sido subestimada por los historiadores de lo religioso. Sin embargo, estos son fundamentales para comprender las diversas estrategias católicas para conquistar un espacio en la sociedad moderna. Tanto por la variedad de temas tratados y de enfoques, como por su diversidad de escalas, desde lo local a lo internacional, los congresos constituyen un medidor muy fiable de las prioridades, objetivos, temores y ensoñaciones del catolicismo finisecular (Sorrel, 2009).

\section{¿Una utopía ultramontana?}

El desmoronamiento de buena parte de los proyectos utópicos que marcaron los siglos XIX y XX así como la dificultad para imaginar alternativas utópicas 
a nuestro presente constituyen sin duda una barrera hermenéutica a la hora de abordar esta cuestión. Y es que además la utopía resulta un objeto de estudio resbaladizo y engañoso ya que, a primera vista, parece hablarnos de otro lugar cuando en realidad se proyecta en otro tiempo. Del mismo modo, aunque la utopía se plantea en términos de diferencia radical con el sistema actual, la otredad no es tal, ya que incluso «nuestras imaginaciones más desatadas no son más que collages de experiencia, constructos compuestos de fragmentos y trozos de aquí y el ahora» (Jameson, 2005: 9).

Además, con frecuencia, la historiografía se centra exclusivamente en aquellas utopías cuyo horizonte se proyecta en el futuro, olvidando que algunas de ellas también volvieron la vista atrás, hacía un pasado idealizado en forma de edad dorada. Tan inexistente e irreal era el futuro por nacer como aquel pasado perdido que se pretendía restaurar. Estas utopías -o retrotopías como las califica Zygmunt Bauman- están marcadas por una sensación de nostalgia por aquel tiempo perdido que se pretende restaurar (Bauman, 2017). Según Svetlana Boym, existen dos tipos de nostalgia: una restaurativa que enfatiza el nostos -el regreso- y espera la reconstrucción del hogar perdido y otra reflexiva que se centra en el dolor y el anhelo. Para nuestro análisis, resulta más interesante la primera ya que se presenta como guardiana de la verdad y la tradición (Boym, 2001, XVIII). Con frecuencia, los estallidos de nostalgia se producen tras épocas convulsas como las revoluciones. Esa nostalgia se expresa no sólo por el Antiguo Régimen o un momento de esplendor sino también por los sueños irrealizados del pasado (Boym, 2001, XVI).

Antes de pasar a abordar cómo el ultramontanismo encaja dentro de este horizonte utópico, resulta necesario realizar una precisión conceptual. A lo largo del artículo se usa ultramontanismo como aquella cosmovisión católica que quería reforzar el poder efectivo y simbólico del Papa para convertirlo en el centro de la vida religiosa y hacer frente a los desafíos del mundo contemporáneo. Este concepto ha sido criticado en la historiografía francesa por su naturaleza polémica y su excesiva asociación con el legitimismo, obviando otras sensibilidades dentro del catolicismo como las liberales. Para solventar estos problemas, desde la historiografía francesa se ha planteado la necesidad de utilizar otros conceptos como romanización, obviando que también tuvo una dimensión polémica al ser utilizado para desacreditar las posiciones infalibilistas en los prolegómenos del Concilio Vaticano I. Romanización plantea el problema de remitir a un proceso de homogeneización romana del mundo católico, obviando la dimensión transnacional de este movimiento y el papel que tuvieron otros centros de referencia católicos a nivel mundial para la configuración del catolicismo moderno (Ramón Solans, 2020b). Por último, para 
definir esta corriente a favor del sometimiento de los gobiernos y las relaciones internacionales a los principios emanados desde la Santa Sede también se ha recurrido a la idea de catolicismo intransigente (Poulat, 1969; Mayeur, 1972). Si bien este concepto sirve para trazar la evolución de la actitud hostil de una parte del catolicismo ante la modernidad, también es cierto que acaba por oscurecer los elementos esencialmente modernos de esta reacción.

¿Cómo encaja el ultramontanismo dentro del horizonte utópico que hemos trazado? Tras la tormenta revolucionaria, muchos católicos volvieron la vista hacia Roma y el papado en busca de consuelo y orientación ante un mundo que no comprendían y que percibían cada vez más alejado de los valores cristianos. Por su parte, las tribulaciones vividas por Pío VI y Pío VII durante las guerras revolucionarias y napoleónicas, y especialmente por Pío IX durante el proceso de unificación italiana que culminaría con la desaparición de los Estados pontificios despertaron una ola de solidaridad a favor del papado que adoptó una gran variedad de formas, desde recogida de firmas y donativos hasta el reclutamiento de voluntarios, los famoso zuavos pontificios, pasando por el desarrollo de una devoción hacia el papa como mártir (Ramón Solans, 2020a; Rusconi, 2010; Pollard, 2005; Viaene, 2002; Guénel, 1998; Horaist, 1995; Zambarbieri, 1990). Ambos procesos condujeron a la idealización del pasado, una arcadia feliz en la que la sociedad estaba regida por los principios del catolicismo. Dos momentos sobresalían en esta idealización del pasado desde el que imaginar nuevos horizontes: el cristianismo primitivo y la historia medieval.

Con el redescubrimiento, restauración y estudio sistemático de las catacumbas romanas en el siglo XIX, se reforzaba la idea de una Roma eterna y mártir, corazón de la cristiandad. Además, de una manera muy temprana, con la epopeya Les Martyrs (1809) de Chateaubriand, se trazaron paralelismos entre las persecuciones sufridas por el cristianismo durante el Imperio romano y las del presente (Boutry, 1979; Riall, 2010; Viaene, 2004). Del mismo modo, los católicos decimonónicos quedaron cautivados por un pasado medieval idealizado como tiempo de fe y tradición. Esta fascinación adoptó las más diversas formas, desde la pasión por la arquitectura gótica que representa Viollet le Duc hasta la novela histórica de temática medieval, pero sobre todo quedó marcado por la reactualización del discurso de cruzada para hacer frente a los enemigos de los nuevos tiempos (Menozzi, 2017 y 1984; Logan, 1997; Miccoli, 1980). Su visión del tiempo histórico comienza pues por un mundo ordenado por la tradición y la religión que se desmorona por la traición de los intelectuales (Lilla, 2016). 
Sin embargo, el catolicismo decimonónico no estaba simplemente dominado por la nostalgia sino que también se proyectaba en el futuro. Y es que, como señala Mark Lilla para los conservadores, los católicos son a su manera tan radicales como los revolucionarios y están tan inmovilizados como ellos por los imaginarios históricos (Lilla, 2016). Así, frente a aquellos ataques al catolicismo como rémora para el progreso desde el positivismo y el protestantismo, una parte de la apologética católica se dedicó a explicar la contribución de esta confesión al desarrollo de la civilización occidental. Además, trataron de encontrar fórmulas que demostraran la armonía entre religión, progreso técnico y desarrollo económico (Lagrée, 2002). Para ello, destacaron la contribución del papa y la Iglesia católica al mantenimiento del orden frente a los excesos del materialismo, el socialismo y el liberalismo.

El proyecto utópico de que todos los países del mundo reconocieran al papa como árbitro internacional respondía a estas dos pulsiones. Así, como veremos, esta era una retrotopía que planteaba recuperar una atribución perdida y, con ella, no sólo reinstalar aquel reino perdido de los Estados Pontificios sino también un mundo regido por la religión y el papa. Sin embargo, esta no era simplemente la restauración de una edad dorada sino que se planteaba como una forma de refundar la hegemonía y el liderazgo del catolicismo en el mundo moderno. El papa emergería pues como el portavoz de la humanidad y su dignidad frente a un mundo cruel guiado exclusivamente por el materialismo.

\section{Del derecho de gentes a la reivindicación del arbitraje internacional}

Tras cerca de cinco millones de muertos como consecuencia de las guerras revolucionarias e imperiales, así como la destrucción de ciudades, cultivos y talleres (Evans, 2017), algunos católicos volvieron la vista atrás hacia una idealizada y unida cristiandad medieval en la que el papa mediaba entre las potencias y reivindicaron la restauración del derecho de gentes como uno de los medios más eficaces para garantizar la paz. Ya en 1799, poco antes de morir, el joven poeta alemán Novalis escribía su Die Christenheit oder Europa, donde expresaba su desasosiego ante un presente desgarrado por las guerras, mientras evocaba su nostalgia por una idealizada Europa cristiana, anterior a la Reforma y unida por el papa. Desde la cultura intransigente, el jesuita y fundador de $\mathrm{La}$ Civiltà cattolica, Luigi Taparelli d'Azeglio planteaba como los diversos países irían convergiendo en una sociedad planetaria, unida y católica, en la que la única guerra posible sería aquella que declarase un tribunal internacional presidido por el papa contra un Estado que contraviniera las normas del derecho de gentes (Menozzi, 2005). 
Fue de la mano del diplomático escocés y protestante, David Urquhart, que la restauración del derecho de gentes entró definitivamente en la agenda católica. Tras su paso por Francia y con el apoyo de destacados prelados como el obispo de Orleans Félix Dupanloup, Urquhart pidió al papa Pío IX que aprovechara el Concilio Vaticano I para proclamar el derecho de gentes en el orbe católico. La propuesta sólo despertó alguna oposición entre los sectores galicanos ya que estaba vinculada a la declaración de la infalibilidad pontificia. Junto con esta medida, Urquhart promovió la creación de un colegio diplomático religioso en Roma cuyo objetivo fuera lograr instaurar la paz mundial. La caída de Roma y la inesperada clausura del Concilio evitaron que se tomara alguna resolución a este respecto (Robinson, 1920: 231-273).

Esta recuperación del derecho de gentes o derecho internacional se enmarca en el desarrollo del pacifismo así como en una búsqueda activa de nuevas fórmulas que previnieran el estallido de guerras entre naciones. Desde la década de 1830, y especialmente a partir de la guerra franco-prusiana de 1870-1871, el arbitraje y la mediación entre países se plantearon como el mejor medio para la resolución de conflictos entre naciones. En el cambio de siglo, estas posturas se verían ratificadas por las conferencias de la Haya que tuvieron lugar en 1899 y 1907 (Ticchi, 2002: 2). Es en este contexto en el que se promueve desde la teología, la historia y el derecho internacional la idea de que el papa puede desempeñar este papel de mediador y árbitro internacional (Ticchi, 2002: 239-250). Esta idea se puede rastrear hasta al menos los trabajos De suprematu principum Germaniae (1677) de Leibniz y Projet de paix perpétuelle (1713) del abate de Saint Pierre, en los que se defendía una especie de tribunal de naciones cristianas presidido por el papa. Esta idea volvió con fuerza en la Europa postrevolucionaria, especialmente con las obras de Joseph de Maistre, Du Pape (1819) y de Félicité de Lamennais, De la religión considérée dans ses rapports avec l'ordre politique et civil (1825) (Armenteros, 2018: 139, $160 \mathrm{y}$ 285).

La defensa de esta atribución papal estaba necesariamente vinculada con el reconocimiento de su primacía en el seno de la Iglesia. El arbitraje internacional aparecía así como una forma de reivindicar hacia fuera, la necesidad de la existencia de los Estados Pontificios, y hacia dentro, la infalibilidad del papa. Así, por ejemplo, en las polémicas que mantuvo en los prolegómenos del Concilio Vaticano I con el teólogo anti-infalibilista Ignaz von Döllinger, el profesor de Historia de la Iglesia en la Universidad de Würzburg y futuro cardenal, Joseph Hergenröther, recordaba el papel de los papas como árbitros de la paz durante la Edad Media para defender la primacía del papado en el seno de la Iglesia y confiaba en que pronto se pudiera restablecer este rol (Hergenröther,1872: 
260). Menos optimista se mostraba el economista católico Charles Périn quién en su estudio sobre el orden internacional recordaba el papel que desempeñó el papado en la regularización de la sociedad internacional en la Edad Media y lamentaba como la secularización impedía que, a pesar de su autoridad moral y doctrinal, el papa fuera reconocido como árbitro ya que podía ser contraproducente para la Iglesia (Périn, 1888: 32, 45-46 y 255-256).

Entre estas apologías de la capacidad del papa como mediador iba a adquirir una gran celebridad la del noble e historiador británico Stanley of Alderley. El especialista en la época de Magallanes intervino en la Cámara de los Lores en julio de 1887 para defender que

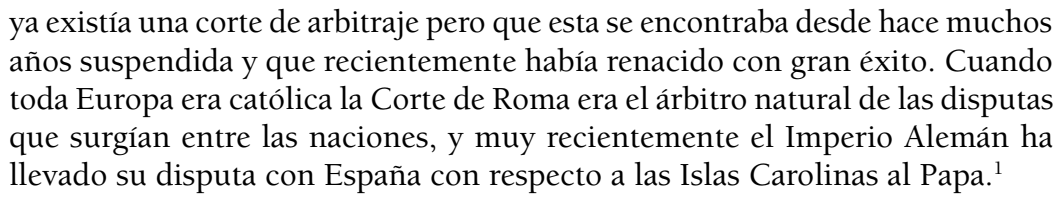

La intervención cobró una especial fama ya que venía de un país anglicano y, por tanto, era una prueba de que la influencia moral del papa iba más allá de las fronteras del catolicismo. Recientemente convertido al islam, Stanley of Alderley señalaba que el papa había condenado la represión de colectivos que pertenecían a otras confesiones como protestantes y musulmanes y que, por lo tanto, su imparcialidad estaba fuera de dudas.

Más allá de estas reivindicaciones más teóricas, la idea del arbitraje del papa fue defendida en diversas asambleas y congresos católicos. Este sería el caso de la Asamblea general de los católicos de Normandía de 1885 en la que el arzobispo de Ruan, el cardenal Thomas, defendió que León XIII se había convertido en el árbitro supremo de los países europeos. Del mismo modo, en los congresos católicos nacionales como los celebrados en Lille (1886), Madrid (1889), Lieja (1890) y Coblenza (1890) se defendió con vehemencia la necesidad de que el papa fuera reconocido como árbitro y mediador en los conflictos internacionales (Chaline, 2015).

La reivindicación fue también desarrollada dentro del catolicismo social como muestran las resoluciones del Congreso de Lieja de 1890. Muy activo en este encuentro, el catedrático de la Facultad de Derecho de la Universidad de Valencia, Rafael Rodríguez de Cepeda llegaba a plantear la extensión de esta idea de arbitraje internacionales para las cuestiones laborales en su discurso «Arbitraje pontificio en materia de legislación internacional acerca del

1. Cámara de los Lores, 25 de julio de 1887. En Hansard's paliamentary debates, vol. 317. London: Cornelius Book, 1887, pp. 1830-1832. 
trabajo». ${ }^{2}$ En el proyecto de mensaje al papa que ideó Cepeda se vinculaba esta capacidad de mediación al «restablecimiento del orden internacional y del orden cristiano, igualmente violados a causa de la situación en que se ha colocado a la Santa Sede». ${ }^{3}$

Por último y no menos importante, esta labor propagandística se vio corroborada por una intensa actividad diplomática vaticana en la resolución de conflictos. Tras algunos intentos frustrados de Pío IX -planteados más bien desde su calidad de jefe de Estado que desde un liderazgo moral y religioso-, León XIII precisaba una efectiva acción político-diplomática y convertía la idea de arbitraje en magisterio pontificio (Menozzi, 2005). En 1885, León XIII consiguió la primera mediación efectiva entre dos países en época contemporánea, la resolución del conflicto entre Alemania y España por las Islas Carolinas. Esta intervención adquirió gran fama en los círculos católicos ya que suponía el reconocimiento diplomático del Vaticano por parte de un soberano protestante, Bismark, y fue visto como una forma de aliviar las tensiones producidas en aquel país por el Kulturkampf. Tras esta actuación, León XIII consiguió mediar efectivamente entre varios países europeos y americanos. Entre los buenos oficios, mediaciones y arbitrajes más destacados estarían los de Portugal y Bélgica (1890), Perú y Ecuador (1893), Haití y Santo Domingo (1895) y Francia y Brasil (1897). Aunque el papa Pecci no dedicara específicamente ningún documento pontificio específicamente a la cuestión de la guerra, en muchas de sus encíclicas, discursos y acciones desveló su preocupación por la conocida como paz armada, advirtiendo sobre su fragilidad y sobre los peligros del desarrollo de la industria armamentística (Hilaire, 2003: 424-425; Ticchi, 2002: 61-166; Cortright, 2008: 200-201).

\section{La defensa del arbitraje en los congresos españoles (1889-1892)}

Durante el pontificado de León XIII surgió y tomó forma lo que la historiografía ha definido como «movimiento católico», entendido como «una organización conjunta y global ligada a unas acciones y movilizaciones, que asume la lucha por la conservación o la reconquista de una sociedad descristianizada o secularizada, desde dentro de las instituciones liberales y en su marco legal» (Montero, 2017:14). En este movimiento, los congresos católicos nacionales desempeñaron un papel central en la coordinación y desarrollo de diversas obras católicas, actuando como vectores de difusión de la estrategia vaticana en cada país. Como señalan Claude Langlois y Christian Sorrel, los congresos

2. La Unión Católica, 12 de septiembre de 1890.

3. La Unión Católica, 18 de septiembre de 1890. 
«ilustran la capacidad de la Iglesia para responder a situaciones inéditas apropiándose o inventando nuevos modos de presencia y de acción, en el campo eclesiástico, social, político o intelectual» (Langlois y Sorrel, 2010: 23). Si bien tanto las temáticas, los enfoques y las escalas de estos congresos fueron muy variados casi todos ellos coincidieron a la hora de manifestar su adhesión a la Santa Sede y reivindicar la soberanía temporal de los pontífices.

En España este movimiento se inicia en 1889 con el Primer Congreso Católico de Madrid y toma forma con los congresos celebrados en Zaragoza (1890), Sevilla (1892), Tarragona (1894), Burgos (1899) y Santiago (1902). A estos congresos asistieron numerosas personalidades del clero y del laicado que discutieron sobre los temas más candentes del catolicismo finisecular. Entre los objetivos marcados por los congresos estarían: coordinar esfuerzos y superar las divisiones en el campo católico, especialmente producidas por los sectores integristas y carlistas, organizar una eficiente propaganda católica que llegara a toda la sociedad y promover distintas obras y asociaciones católicas. Los sectores integristas y carlistas plantearon un serio desafío al proyecto católico ultramontano ya que se saltaban con frecuencia la jerarquía católica y apelaban directamente a la autoridad del papa (Hibbs-Lissourgues, 1995: 347-351).

Al igual que sus pares europeos, los congresos españoles se plantearon también como una reivindicación de los Estados Pontificios y una expresión de la solidaridad de la Iglesia española con el papa. El primer congreso celebrado en España tuvo lugar en abril y mayo de 1889 en la Iglesia de San Jerónimo el Real de Madrid y fue organizado por el entonces obispo auxiliar de Toledo y uno de los prelados más activos del fin de siglo, Ciriaco Sancha. En este congreso encontramos numerosas expresiones de adhesión a la Santa Sede y defensa de la soberanía temporal del pontífice. En su segunda sesión, el catedrático de derecho natural de la Universidad de Sevilla, carlista y promotor de la Liga católica de Sevilla, Manuel Sánchez de Castro pronunció un encendido discurso a favor de la soberanía temporal de los pontífices, con el argumento tantas veces repetido de que los papas «necesitan de su libertad e independencia para ejercer su divino magisterio». Para Sánchez de Castro, «la civilización de Europa es obra del pontificado»y, por tanto, la existencia del papado es fundamental para mantener la justicia y la verdad en las relaciones internacionales, especialmente con las naciones oprimidas o más débiles. Por ello, se preguntaba « ¿quién sino los Papas son la garantía de Irlanda? ¿no fue el Papa mediador en la cuestión de las Carolinas?». ${ }^{4}$

4. La Unión Católica, 25 de abril de 1889. 
Este discurso, saludado por los medios integristas y posibilistas, sirvió de base para el que pronunció el canónigo de la catedral de Cádiz, Benito Murúa, sobre los «Medios para hacer prevalecer el arbitraje de los romanos» y que entendía que su capacidad de mediación no era más que el corolario de los derechos del papa expuestos en sesiones anteriores. Este prometedor eclesiástico, que llegaría a ser arzobispo de Burgos, describía con preocupación la situación actual en la que «la paz armada de hoy no es más que una guerra permanente» y de nada han servido los congresos por la paz que se han celebrado desde $1814 .{ }^{5}$ Las palabras de Benito Murúa se ajustaban perfectamente al espíritu de la alocución que había pronunciado León XIII el 11 de febrero de aquel mismo año y en las que expresaba su preocupación por esta paz armada. Ante esta situación, Murúa recordaba el arbitraje internacional que habían desempeñado los papas en la Edad Media y que en el presente ejercía León XIII. La justificación de esta intervención se basaba en los valores de «prudencia, sabiduría y justicia de que están dotados los Pontífices» así como por el hecho de que:

el papa tiene súbditos en todos los imperios. La Iglesia tiene intereses en todas las naciones. Es así que todas las naciones defienden a sus súbditos y a sus intereses, luego, la Iglesia tiene derecho a intervenir en los conflictos de todas las naciones, en defensa de la paz. ${ }^{6}$

Al igual que en otros congresos católicos coetáneos, Murúa ligaba el arbitraje internacional con el poder temporal, «¿Puede ejercer el papa este carácter encadenado con la ley de garantías, amordazado con el Código penal y prisionero en el Vaticano?». El entonces canónigo señalaba que era necesario el concurso de la prensa y los congresos y asambleas para defender tanto el arbitraje de los papas como su poder temporal.

En la sexta sesión intervino el eclesiástico orientalista Urbano Ferreiroa para seguir defendiendo el arbitraje de los pontífices desde la Edad Media, época en la que «los papas estuvieron próximos a realizar tan hermoso ideal». Entonces actuaban como árbitros supremos

de las diferencias entre los príncipes y los pueblos, defensores de la justicia pública, pacificadores del mundo arruinado por guerras calamitosas, centros del poder público, religioso e internacional, investidos por la fuerza de las cosas de una magistratura suprema, reyes, príncipes y pueblos estaban sometidos a ellos indistintamente, completando el Supremo tribunal del Papa la organización social. ¡Tribunal beneficioso para los pueblos oprimidos y vejados! Excomulgaba a los tiranuelos feudales, convertía las iglesias en lugares

5. La Unión Católica, 29 de abril de 1889.

6. La Unión Católica, 29 de abril de 1889. 
de refugio, trabajaba incansablemente por la paz de los Estados, establecía la tregua de Dios, defendía enérgicamente el celibato eclesiástico, impidiendo así que el sacerdocio católico fuese convertido en una casta. Y de pacificar los Estados no se cansaron nunca los Papas. Con razón el protestante Sismondi los llama pacificadores de los grandes. ${ }^{7}$

En octubre de 1890 se celebró el segundo Congreso nacional en Zaragoza. Al igual que en el encuentro de Madrid, los asistentes se solidarizaron con la situación del papa e hicieron llamamientos a la unidad de los católicos. Celebrado en vísperas de la célebre encíclica social Rerum Novarum del 15 de mayo de 1891, el congreso zaragozano ilustra la existencia de una conciencia social en el catolicismo español que iba más allá de respuestas meramente benéficas (Montero, 1983:183). Además, en aquel encuentro, los discursos incidieron todavía más en la importancia de la soberanía temporal de los papas y su papel como árbitros internacionales. En un tono triunfalista, el político conservador y fuerista navarro, Antonio Morales y Gómez, se formulaba una serie de preguntas sobre las razones del renovado papel del papado en la esfera internacional:

¿Por qué revive en las naciones el más profundo respeto a un poder que parecía expirante? ¿Qué significa esa protesta que no cesa contra la usurpación? ¿Por qué sigue considerado el supremo pontífice como ejerciendo soberanía temporal, mientras todas las potencias, aun aquellas que no profesan el catolicismo, evitan cuidadosamente en sus relaciones con la Italia reconocer un estado de derecho que ésta con tanto afán anhela? ¿Cuál es la causa de que, después de dos siglos en que parecía olvidado el arbitraje de los papas, se resucite, a instancias nada menos que de una nación protestante? ¿Por qué todos los grandes políticos y profundos pensadores de diferentes cultos y creencias manifiestan sus opiniones favorables a la independencia de, la Sede Apostólica, y por ende el restablecimiento del poder temporal? (Citado en Carbonero y Sol, 1890a: 172-173).

El diputado conservador trazaba un oscuro panorama de paces armadas y arbitrajes de grandes potencias que sólo buscan consolidar su poder. Frente a esta desoladora situación, para Morales y Gómez, sólo se alza «una luz purísima» que «irradia desde el Vaticano» y

dirige su voz paternal a los soberanos de la tierra y les recuerda sus deberes a las naciones y les predica la paz, y en los grandes conflictos la asegura por medio de rectos e imparciales arbitrajes; advierte los peligros de esa misma paz armada, y quiere que sea fruto del triunfo de la justicia, de la proclamación del derecho por todos respetado, prediciendo la ruina de las naciones si continúa el mal por algún tiempo (Citado en Carbonero y Sol, 1890a: 173).

7. La Unión Católica, 2 de mayo de 1889. 
La intervención del catedrático de Economía política de la Universidad de Zaragoza, el marqués de Valle Ameno, ha sido destacada como una de las más evolucionadas en el marco del incipiente catolicismo social en España (Montero, 1983: 154). El discurso de este profesor universitario y activista católico también coincidía con los anteriores a la hora de destacar la primacía del papa en el orden diplomático señalando cómo

Gobiernos infieles y protestantes han mantenido y mantienen relaciones directas con la Santa Sede. No obstan los esfuerzos del luteranismo para que los príncipes teman y respeten el Concilio de Trento, y cuando la revolución ha roto esos vínculos ha tenido necesidad de reanudar las relaciones en Francia, en Bélgica, en Alemania, en Inglaterra, ora porque se reconozca en ella una fuerza moral considerable que es preciso temer y con la que es necesario negociar, ora diciendo como Napoleón: «tratad al pontífice como si estuviera al frente de 200.000 hombres», porque mucho más que ejércitos formidables implica el poder espiritual de la Iglesia, poder cuya influencia es protectora a los poderes seculares, como curaba la sombra de San Pedro y vigorizaba a los enfermos (Citado en Carbonero y Sol, 1890a: 177).

La última intervención que nos interesa traer a colación es la del director de la revista La Cruz y uno de los periodistas católicos más importantes del siglo XIX español, León Carbonero y Sol. Destacado ultramontano, el conde de Sol intervino en el Congreso de Zaragoza en representación del obispo de Málaga para defender la imprescriptibilidad de la soberanía pontificia, «el papa no ha perdido ni puede perder por la ocupación material de Roma su majestad y su influencia, ni su cualidad de Rey temporal, y actos son de veneración y confianza en ese poder los que estamos presenciando en nuestros días» (Carbonero y Sol, 1890b: 43). En su argumentación, León Carbonero y Sol señalaba cómo la capacidad de arbitrio del papa era reconocida incluso por protestantes como el filósofo Leibniz, el primer ministro británico William Pitt, el parlamentario británico Lord Robert Montagu o el historiador Simonde de Sismondi (Carbonero y Sol, 1890b: 43-44). Esto convertía al papa en la figura más importante en el orden internacional:

¿No ha de ser Rey, no es Rey de hecho y de derecho, ese hombre providencial a quien todas las naciones buscan y al que se someten en las situaciones más difíciles? Sí; lo ha sido, lo es y lo será, porque es árbitro y moderador de las naciones, y por eso, según dice Gregorio IX, tiene su silla en Roma, entre Oriente y Occidente; porque es Príncipe de los Príncipes, tiene la monarquía entre todos y sobre todos; porque su autoridad es tan extensa que no tiene superior alguno sobre la tierra, puede obligar a los Príncipes a que administren justicia y desligar a los súbditos del juramento de fidelidad (Carbonero y Sol, 1890b: 44-45). 
Los actores católicos no se limitaron a los congresos confesionales sino que trataron de defender el arbitraje del papa en otro tipo de encuentros seculares. Este sería el caso del Congreso jurídico iberoamericano que se reunió en 1892 en Madrid con motivo de los festejos por el IV Centenario del descubrimiento de América. Dentro de la exaltación de una comunidad supranacional iberoamericana, este encuentro planteaba crear un marco de mediación y arbitraje para los problemas diplomáticos que pudieran surgir entre España, Portugal y las diferentes republicas latinoamericanas.

El encargado de defender el arbitraje pontificio en el congreso fue el político conservador ecuatoriano Pablo Herrera. Este antiguo ministro de los gobiernos de García Moreno e Ignacio Veintemilla acababa de lograr un gran triunfo al alcanzar un acuerdo con Perú para la resolución de la cuestión limítrofe en la frontera amazónica. El político ecuatoriano hacía un recorrido por los diversos intentos de lograr una federación americana así como de los proyectos de arbitraje internacional en 1889 para luego recuperar el proyecto de Stanley of Alderley de convertir al papa en árbitro internacional ya que

ninguna autoridad reúne como el supremo pastor de la Iglesia las condiciones indispensables para obtener la confianza de las partes, cuyas diferencias someten a su decisión. Sabiduría, imparcialidad, rectitud, probidad incontrastable, amor a la justicia son las dotes características del sucesor de San Pedro. ¡Cuánto no deben la libertad y la civilización de los pueblos a la influencia del pontificado! ${ }^{8}$

Al igual que otras apologías a favor del arbitraje internacional, Pablo Herrera recurría a los ejemplos de autores protestantes como el historiador prusiano Jean Pierre Fréderic Ancillon y el filósofo Leibniz para mostrar que la influencia moral del papa no se reducía al ámbito del catolicismo. Incluso políticos liberales como Segismundo Moret, aunque finalmente se decantaran por otros modelos de arbitraje, reconocieron en el encuentro la capacidad mediadora del papado y exaltaron el papel de León XIII en la resolución del enfrentamiento entre España y Alemania por las Islas Carolinas. ${ }^{9}$ No en vano, aquel acuerdo se había logrado durante el gobierno del también liberal Práxedes Mateo Sagasta. La propuesta no fue finalmente aceptada y las conclusiones del congreso se limitaron a subrayar la necesidad del arbitraje para la resolución de conflictos.

Aunque finalmente no fuera discutida en el Congreso jurídico iberoamericano, la propuesta del obispo de Montevideo, Mariano Soler, constituye una buena síntesis de los argumentos que se movilizaron a favor del arbitraje

8. Congreso jurídico ibero-americano reunido en Madrid el año 1892. Madrid: Real Academia de Jurisprudencia y Legislación, 1893, 76.

9. Ibídem, 80. 
internacional del papado así como del apoyo que suscitaba al otro lado del Atlántico. Aunque fue invitado a dicha reunión, Mariano Soler no pudo asistir y delegó el discurso que tenía pensado en el ministro plenipotenciario del Uruguay ante España, el poeta católico Juan Zorrilla de San Martin. La intención de Soler era lograr que el papa fuera nombrado árbitro internacional de la paz en las naciones iberoamericanas como paso previo a que fuera reconocido a escala global. Para lograr tan ansiado objetivo, Soler planteaba además la necesidad de restablecer el derecho de gentes para que el orden internacional esté basado sobre el viejo principio de «no hacer a las demás naciones lo que no se desea para la propia; hacer a las demás lo que se quiere para la suya». Sólo el papa reunía los requisitos para actuar ya que las pretensiones de las naciones poderosas son irreconciliables y las naciones pequeñas son influenciables por las grandes. Además, el papa es una autoridad a la que

los fieles de todas las naciones, de todas las lenguas rinden igual acatamiento y a quien los no creyentes reconocen imparcialidad, y para quien todos los pueblos son igualmente caros siendo el único libre a toda sospecha. ${ }^{10}$

Para justificar su decisión Soler recurría a argumentos políticos e históricos, centrándose en el papel que desempeñó durante la Edad Media y destacando cómo reconocidos protestantes habían subrayado su valía como árbitro de la paz: el filósofo Leibniz, el publicista David Urquhart y, más recientemente, el canciller Bismark. ${ }^{11}$ A pesar de su petición, el discurso de Juan Zorrilla de San Martín finalmente se limitó a exaltar la inspiración católica del descubrimiento de América. ${ }^{12}$ Esto es debido probablemente a que Zorrilla de San Martín quedó encargado de la presentación del congreso y las mesas.

Por último, los católicos defendieron el derecho del papa a estar presente en la conferencia de la Haya de 1899 para lograr un acuerdo sobre un tribunal de arbitraje internacional. Al terminar el congreso, La Lectura Dominical, órgano del apostolado de la prensa, señalaba en un artículo el fracaso que había supuesto la conferencia de La Haya ya que no había resuelto ni las tensiones a propósito de la posible disolución de los imperios Austro-húngaro y Otomano, ni las tiranteces entre Francia y Alemania, etc. Se habla de paz

10. «Carta de Mariano Soler a Juan Zorrilla de San Martín (Montevideo, 5 de agosto de 1892)», en Museo Histórico Nacional, Casa Lavalleja, Vol. 2138 Documentos Relativos al Arzobispo Mariano Soler con el Dr. Juan Zorrilla de San Martin, 1885-1908, Carpeta 1 Correspondencia de Monseñor Mariano Soler con el Dr. Juan Zorrilla de San Martin, 1885-1908, Carpetín 5, 1890-1896.

11. Ibídem.

12. Congreso jurídico ibero-americano reunido en Madrid el año 1892, Madrid, Real Academia de Jurisprudencia y Legislación, 1893, pp. 38-39. 
universal pero «el suelo está sembrado de pólvora; pasean por él muchos con antorchas encendidas en las manos, y se discute seriamente acerca de cómo se evitará que la pólvora llegue a inflamarse». ${ }^{13}$ Ante esta situación, la exclusión del papa era considerada como inexplicable ya que

la calidad de mediador de la paz es una investidura que poseen los Romanos Pontifices, y que arranca: primero, de la voluntad divina de Jesucristo que fundó la Iglesia y el Pontificado; segundo, de la tradición muchas veces secular, y tercero, de la esencia misma del Pontificado Supremo. ${ }^{14}$

Además, el artículo insistía en que su autoridad se elevaba por encima de los intereses particulares y era reconocida hasta por autores protestantes. La presencia del papa había sido requerida por grandes potencias no católicas como Rusia, Holanda y Gran Bretaña y finalmente sólo había sido vetada por un país católico, Italia. El redactor de la noticia destacaba cómo incluso

la joven reina de Holanda, nacida y educada en la secta calvinista, acostumbrada desde la niñez a despreciar la autoridad del Romano Pontífice; pero sin los odios satánicos de los italianísimos a la Santa Sede, escribió a Su Santidad León XIII solicitando su apoyo moral para la obra del congreso. ${ }^{15}$

Precisamente, en la última sesión de la Conferencia de la Haya se leyó la carta de invitación al congreso que la reina Guillermina de Holanda había escrito al papa el 7 de mayo de 1899 así como la respuesta de León XIII del 29 de mayo. Pronto el contenido de ambas misivas trascendió a los medios y fue reproducido por periódicos de todo el mundo. En su invitación, la reina Guillermina destacaba cómo la voz del papa «se ha elevado siempre a favor de la paz». Por su parte León XIII agradecía especialmente la invitación y señalaba cómo la promoción de la paz era propia a su ministerio por voluntad divina y por tradición. Además, el papa señalaba que

la autoridad del supremo pontificado traspone, en efecto, las fronteras de las naciones; abraza a todos los pueblos, a fin de confederarlos en la verdadera paz del Evangelio; su acción para promover el bien general de la humanidad se eleva por encima de los intereses particulares que constituyen el objetivo de los diversos jefes de Estado, y sabe mejor que nadie inclinar a la concordia a tantos pueblos de tan distinto carácter. La historia a su vez viene a testimoniar todo lo que nuestros predecesores han hecho para dulcificar con su influencia las leyes desgraciadamente inevitables de la guerra; impedir luchas sangrientas... ${ }^{16}$

13. La Lectura Dominical, 13 de agosto de 1899.

14. Ibídem.

15. La Lectura Dominical, 13 de agosto de 1899.

16. El Correo Militar, 9 de agosto de 1899. 
Además, León XIII recurría a su mediación entre Alemania y España por las Islas Carolinas así como a otros ejemplos en Sudamérica para justificar su asistencia a la Conferencia de La Haya así como su propio papel en la esfera internacional. La carta, como destacaba La Dinastía, era otra prueba más de que «el papa hubiera sido el más autorizado miembro de la conferencia, el que con mayor éxito podía haber levantado su voz augusta». ${ }^{17}$

La exclusión del papa en la conferencia de la Haya fue la protagonista del V Congreso católico nacional celebrado en Burgos en 1899. Tras los congresos católicos nacionales de Sevilla (1892) y Tarragona (1894) en los que el arbitraje internacional no había sido abordado, esta cuestión volvió a ocupar un lugar muy relevante en las intervenciones que se produjeron en Burgos. Para explicar el interés renovado de los católicos españoles por el arbitraje internacional habría que recordar que un año antes del V Congreso católico nacional, en 1898, León XIII había mediado sin éxito entre el gobierno estadounidense de William Mackinley y el español de Sagasta a cuenta de la crisis del Maine y que acabaría con la pérdida de las últimas colonias españolas de ultramar.

En el congreso de Burgos destacó la intervención del catedrático de Derecho administrativo de la Universidad de Valladolid, Antonio Royo Villanova. En su intervención el director de El Norte de Castilla ofrecía una de las más completas y acabadas visiones de esta utopía del derecho internacional cristiano. Al igual que en anteriores discursos, Royo Villanova partía de una visión idealizada de la Edad Media con un orden internacional bajo la autoridad moral de los papas. Este orden se había perdido con la Reforma protestante y las guerras de religión que habían alumbrado «el derecho internacional moderno fundado en el antagonismo de intereses y en la lucha de pueblos y de razas, y basado en el predominio de la fuerza». ${ }^{18}$ Por ello, para Royo Villanova la realización de este proyecto utópico pasaría necesariamente por uno de los elementos clásicos del milenarismo, la reconciliación y retorno del resto de confesiones cristianas al catolicismo:

Yo tengo confianza en que esos pueblos cristianos apartados del seno de la Iglesia comprenderán que tienen mucho de común con los católicos y que juntos debemos combatir ese materialismo feroz que todo lo invade y todo lo domina. Yo creo que esos pueblos cristianos confesarán su error y advertirán los daños que han causado a los intereses morales del mundo sembrando el cisma y la división en la gran familia; comprenderán que el poder de los papas es la única fuerza moral que por su grandeza puede contrarrestar el

17. La Dinastía, 9 de agosto de 1899.

18. Quinto Congreso católico español, celebrado en Burgos el año 1899. Burgos: Imprenta y estereotipia de Polo, 1899, 93. 
positivismo imperante. Yo creo que la sinceridad de sus creencias les hará desear la reconstitución del orbe cristiano, la cual solo es posible dentro de la Iglesia católica, que con su fe, su dogma, y su disciplina, constituiría un núcleo vigoroso de concentración para la humanidad y realizaría el triunfo definitivo del espíritu sobre la materia. Esta aspiración generosa no es ciertamente una quimera, sino una esperanza razonable. ${ }^{19}$

Para estos actores, como bien prueban las palabras de Royo Villanova, estos no son proyectos utópicos sino plenamente realizables. En este caso el elemento que le otorga plausibilidad y lo conecta con su presente es la necesidad que tienen las diversas corrientes cristianas de hacer frente a sus enemigos comunes. Tras la unión de los pueblos cristianos vendría algo todavía menos plausible, la conversión del resto de habitantes del planeta al catolicismo:

entonces podría reinar la paz entre los hombres, apoyada, no en la fuerza de los ejércitos, sino en la autoridad moral de los papas, mediadores naturales entre los príncipes para evitar sus diferencias, y árbitros imparciales entre los Estados para resolver sus conflictos. Entonces y solo entonces podría ser perfecto el derecho internacional. ${ }^{20}$

Además, Rollo Villanova planteaba que el arbitraje internacional de los papas ofrecía innegables ventajas a «los príncipes y las repúblicas» que desconfiaban de la mediación de otros países que podían actuar según sus intereses. Frente a ello, los pontífices «no aspiran a la dominación, ni a la conquista, ni a la dirección siquiera de los intereses temporales; sino que tienen a su cargo el cuidado de las almas y realizan en el mundo como representantes de Jesucristo una misión de paz». ${ }^{21}$

Por último, Royo Villanova criticaba que no se hubiera permitido al papa asistir a la Conferencia de La Haya. Su ausencia había condenado a la conferencia de paz al fracaso ya que no se había acordado nada respecto al desarme y se había hablado "platónicamente» del arbitraje. Además, para este jurista de origen aragonés, aquello que se había conseguido, no era ninguna novedad dentro del catolicismo ya que tiene «sus precedentes en antiguos preceptos de la Iglesia (como la célebre Decretal de Inocencio III prohibiendo el uso de ciertas armas, y las disposiciones del concilio de Clermont para proteger a las personas que no formaban parte de los ejércitos) ${ }^{22}$

La intervención del director del Instituto de Orense, Marcelo Macías vino a insistir en algunas de las cuestiones esbozadas por Royo Villanova, criticando

19. Ibídem, 110.

20. Ibídem, 111.

21. Ibídem, 111

22. Ibídem, 112-113.

Pasado y Memoria. Revista de Historia Contemporánea, 23, 2021, pp. 117-138 
que León XIII no hubiera podido participar en la Conferencia de la Haya. Para ello, citaba la mencionada invitación de la reina Guillermina y manifestaba la doble injusticia que suponía que al papa se le hubiera despojado de su soberanía temporal, justificándolo por el hecho de que se debía liberar al papa de los negocios temporales para que se dedicara a lo espiritual y

hoy que le ven despojado de su antigua realeza, sometido a otro monarca y recluido en el interior del Vaticano, hoy prescinden de su concurso efectivo en asunto tan arduo y eminentemente cristiano como el de la paz del mundo, pretextando que no pueden ni deben lastimarse los supuestos derechos del reino de Italia. Es decir, que por no ser de hecho rey temporal, no tiene derecho a tomar asiento en el consejo de las naciones. ¿Puede darse prueba más palmaria y concluyente de la necesidad, de la absoluta e imperiosísima necesidad de que le sea devuelto el principado civil, sin el cual no le es dado cooperar de una manera efectiva en asunto tan íntimamente enlazado con su augusto ministerio ${ }^{23}$

\section{Conclusiones}

La utopía de un mundo en el que las relaciones diplomáticas estuvieran regidas por el papa comenzó a tomar forma en la segunda mitad del siglo XIX. Conforme disminuía el poder temporal de los pontífices, especialmente a partir de la desaparición de los Estados Pontificios, los católicos comenzaron a imaginar nuevas formas de reinscribir su autoridad moral en el concierto de las naciones. Para justificar esta propuesta, volvieron la vista atrás hacia un pasado medieval idealizado y desde allí se proyectaron en el presente y el futuro con el objetivo de explicar el nuevo rol que iba a desempeñar el catolicismo y el Vaticano en el mundo moderno.

Este proyecto fue el resultado de una campaña global, impulsada simultáneamente desde Roma -a través de la acción diplomática y doctrinal del papa- y desde el resto del mundo católico -mediante la prensa, la apologética y la obra de los congresos católicos entre otras. En España, esta visión utópica fue promovida en los congresos católicos nacionales así como en la prensa escrita. Los argumentos y los autores de referencia eran similares a los de otros países europeos y americanos. Los discursos coincidían a la hora de asociar esta atribución papal con la defensa de su soberanía temporal. Asimismo, para legitimar este proyecto, los oradores solían recurrir a una visión idealizada del arbitraje papal en la Edad Media así como a su carácter supraconfesional ya que su capacidad era reconocida tanto por pensadores como por gobernantes protestantes.

23. Ibídem, 203. 
Si bien esta utopía ultramontana nunca llegó a materializarse, sí que desempeñó un papel central a la hora de reinventar la autoridad del papa, legitimando la transición desde una monarquía feudal a un moderno soft power a escala global. Así, la campaña transnacional a favor del arbitraje papal de los conflictos diplomáticos es un factor clave para entender la importancia que tiene en el presente una pequeña ciudad estado en la esfera internacional. Además, en los siglos XX y XXI, las actuaciones de Benedicto XV durante la Primera Guerra Mundial, Juan Pablo II durante la Guerra fría y el conflicto del Beagle entre Chile y Argentina o, más recientemente, la mediación de Francisco I entre Estados Unidos y Cuba, reforzaron el carisma internacional del papado como mediador internacional.

\section{Bibliografía}

ARMENTEROS, Carolina (2018). La idea francesa de la historia: Joseph de Maistre y sus herederos. Zaragoza: Prensas Universitarias de Zaragoza.

BAUMAN, Zygmunt (2017). Retrotopía. Barcelona: Paidós.

BOUTRY, Philippe (1979). Les saints des Catacombes. Itinéraires français d'une piété ultramontaine (1800-1881). Mélanges de l'Ecole française de Rome, 91, 875-930. https://doi.org/10.3406/mefr.1979.2519

BOYM, Svetlana (2001). The Future of Nostalgia. Nueva York: Basic Books.

BRENNAN, Brian (2000). Visiting 'Peter in Chains': French Pilgrimage to Rome, 1873-93. The Journal of Ecclesiastical History, 51-4, 741-766. https://doi. org/10.1017/S0022046900005121

CARBONERO Y SOL, León (1890a). Crónica del segundo congreso católico nacional español celebrado en Zaragoza. Madrid: Est. Tipográfico «Sucesores de Rivadeneyra».

CARBONERO Y SOL, León (1890b). Discurso sobre la necesidad del principado civil en la Santa Sede, aprobado por la Junta Central de Organización Católica de España para leerle en el Congreso Católico de Zaragoza, Segundo Nacional Español. Madrid: Madrid, Est. Tipográfico «Sucesores de Rivadeneyra».

CHALINE, Nadine-Josette (2015). Empêcher la guerre. Le pacifisme du debut du XIXe siècle à la veille de la Seconde guerre mondiale. Amiens: Encrage.

CORTRIGHT, David (2008). Peace. A History of Movements and Ideas. Cambridge: Cambridge University Press. https://doi.org/10.1017/CBO9780511812675

EVANS, Richard J. (2017). La lucha por el poder: Europa 1815-1914. Barcelona: Crítica.

GUÉNEL, Jean (1998). La dernière guerre du pape. Les Zouaves pontificaux au secours du Saint-Siège (1860-1870). Rennes: Presses Universitaires de Rennes. 
HERGENRÖTHER, Joseph (1872). Katholische Kirche und christlicher Staat in ihrer geschichtlichen Entwicklung und in Beziehung auf die Fragen der Gegenwart, Vol. 1. Friburg im Bresigau: Herder.

HIBBS-LISSOURGUES, Solange (1995) Iglesia, prensa y sociedad en España (18681904). Alicante: Instituto de Cultura «Juan Gil Albert».

HILAIRE, Yves-Marie (2003). Léon XIII, un pape moderne? (1878-1903). En Yves-Marie HILAIRE (dir). Histoire de la papauté. 2000 ans de mission et de tribulations. París: Seuil.

HORAIST, Bruno (1995). La Dévotion au Pape et les catholiques français sous le pontificat de Pie IX (1846-1878). D’après les Archives de la Bibliothèque Apostolique Vaticane. Rome : École Français de Rome.

JAMESON, Fredric (2005). Arqueologías del futuro. El deseo llamado utopía y otras aproximaciones de ciencia ficción. Barcelona: Akal.

LAGRÉE, Michel (2002). Religion et modernité. France XIX-XXème siècles. Rennes: Presses Universitaires de Rennes. https://doi.org/10.4000/books.pur.11082

LANGLOIS, Claude y SORREL, Christian (2010). Le temps des congrès catholiques. Bibliographie raisonnée des actes des congrès tenus en France de 1870 à nos jours. Turnhout: Brepols. https://doi.org/10.1484/M.BEHE-EB.5.106536

LILLA, Mark (2016). The Shipwrecked Mind: On Political Reaction. New York: New York Review Books.

LOGAN, Oliver (1997). Christian civilization and Italic civilization: Italian Catholic theses from Gioberti to Pius XII. Studies in Church History, 33, 475-486. https:// doi.org/10.1017/S0424208400013401

MAYEUR, Jean-Marie (1972), Catholicisme intransigean, catholicisme social, démocratie chrétienne. Annales, 27-2, 483-499. https://doi.org/10.3406/ ahess. 1972.422514

MICCOLI, Giovanni (1980). Chiesa e società in Italia tra ottocento e novecento: il mito della «Cristianità». En Giuseppe ALBERIGO et al., Chiese nella società. Verso un superamento della cristianità (153-245). Turin: Marietti.

MENOZZI, Daniele (1984). La Chiesa e la storia. Una dimensione della cristianita da Leone XIII al Vaticano II, Cristianesimo nella storia, 5, 69-106.

MENOZZI, Daniele (2005). Ideologia di cristianità e pratica della «guerra giusta». En Mimmo FRANZINELLI y Riccardo BOTTONI (eds.), Chiesa e guerra: dalla benedizione delle armi alla Pacem in terris (91-127). Bolonia: Il Mulino.

MENOZZI, Daniele (2017). I gesuiti alla «nona crociata». Lattualizzazione di un mito nella lotta contro l'unificazione italiana, Humanitas, 72, 838-847.

MONTERO, Feliciano (1983). El primer catolicismo social y la «Rerum Novarum» en España (1889-1902). Madrid: CSIC.

MONTERO, Feliciano (2017). El movimiento católico en España, 1889-1936. Alcalá de Henares: Universidad de Alcalá, Servicio de Publicaciones. 
PÉCOUT, Gilles (2017). La Repubblica romana. En A. GIARDINA (ed.). Storia mondiale dell'Italia (519-523). Roma-Bari: Laterza.

PÉRIN, Charles (1888), L'ordre international. París: Librairie Victor Lecoffre.

POLLARD, John F. (2005). Money and the Rise of the Modern papacy. Financing the Vatican 1850-1950. Cambridge: Cambridge University Press.

POULAT, Émile (1969), Intégrisme et catholicisme intégral. Un réseau secret international antimoderniste: la «Sapinière». París: Casterman.

RAMÓN SOLANS, Francisco Javier (2020a). The Roman Question in Latin America: Italian unification and the development of a transatlantic Ultramontane movement. Atlantic Studies. https://doi.org/10.1080/14788810.2019.1710089

RAMÓN SOLANS, Francisco Javier (2020b). Más allá de los Andes: los orígenes ultramontanos de una Iglesia latinoamericana (1851-1910). Bilbao: Universidad del País Vasco.

RIALL, Lucy (2010). Martyr Cults in Nineteenth-Century Italy. The Journal of Modern History, 82, 255-287. https://doi.org/10.1086/651534

RUSCONI, Roberto (2010). Santo padre. Roma: Viella.

ROBINSON, Gertrude (1920). David Urquhart. Some chapters in the Life of a Victorian knight-errant of justice and liberty. Oxford: Basil Blackwell.

SEILER, Jörg (2007). Somatische Solidarität als Moment ultramontaner Kommunikation. Die Inszenierung der Körperlichkeit Pius IX in der Rottenburger Bistumszeitung. Schweizerische Zeitschrift für Religionsund Kulturgeschichte, 101, 77-106.

SORREL, Christian (2009). Introduction. En Claude LANGLOIS y Christian SORREL (eds.), Le Catholicisme en Congrès (XIXe-XXe siècles). Actes de la table ronde organisée à l'Institut européen en sciences des religions, Paris, 22-23 septembre 2005 (5-8). Paris: Laboratoire de Recherche Historique Rhône-Alpes. TICCHI, Jean-Marc (2002). Aux frontières de la paix: bons offices, médiations, arbitrages du Saint-Siège: 1878-1922. Roma : École Française de Rome.

VIAENE, Vincent (2004). The Roman Question, Catholic Mobilisation and Papal Diplomacy. En Emiel LAMBERTS (ed.), The Black International, 1870-1878 (135-177). Leuven: Leuven University Press.

VIAENE, Vincent (2004). Gladiators of Expiation: the Cult of the Martyrs in the Catholic Revival of the Nineteenth Century. Studies in Church History, 40, 301-316. https://doi.org/10.1017/S0424208400002953

VIAENE, Vincent (2005). Reality and Image in the Pontificate of Leo XIII. En Vincent VIAENE (ed.), The Papacy and the New World, Vatican Diplomacy, Catholic Opinion and International Politics at the Time of Leo XIII, 1878-1903 (9-29). Lovaina: Leuven University Press.

ZAMBARBIERI, Annibale (1990). La devozione al papa. En Elio GUERRIERO y Annibale ZAMBARBIERI (eds.), Storia della chiesa. La chiesa e la società industriale, vol. XX/2 (9-81). Milán: Paoline. 